\title{
Congenital inferior vena cava anomalies: a review of findings at multidetector computed tomography and magnetic resonance imaging*
}

Anomalias congênitas da veia cava inferior: revisão dos achados na tomografia computadorizada multidetectores e ressonância magnética

\author{
Catherine Yang ${ }^{1}$, Henrique Simão $\operatorname{Trad}^{2}$, Silvana Machado Mendonça ${ }^{3}$, Clovis Simão $\operatorname{Trad}^{4}$
}

\begin{abstract}
Inferior vena cava anomalies are rare, occurring in up to $8.7 \%$ of the population, as left renal vein anomalies are considered. The inferior vena cava develops from the sixth to the eighth gestational weeks, originating from three paired embryonic veins, namely the subcardinal, supracardinal and postcardinal veins. This complex ontogenesis of the inferior vena cava, with multiple anastomoses between the pairs of embryonic veins, leads to a number of anatomic variations in the venous return from the abdomen and lower limbs. Some of such variations have significant clinical and surgical implications related to other cardiovascular anomalies and in some cases associated with venous thrombosis of lower limbs, particularly in young adults. The authors reviewed images of ten patients with inferior vena cava anomalies, three of them with deep venous thrombosis. The authors highlight the major findings of inferior vena cava anomalies at multidetector computed tomography and magnetic resonance imaging, correlating them the embryonic development and demonstrating the main alternative pathways for venous drainage. The knowledge on the inferior vena cava anomalies is critical in the assessment of abdominal images to avoid misdiagnosis and to indicate the possibility of associated anomalies, besides clinical and surgical implications.
\end{abstract}

Keywords: Inferior vena cava; Congenital abnormalities; Venous thrombosis.

Resumo Anomalias da veia cava inferior são incomuns, ocorrendo em até $8,7 \%$ da população, quando consideradas as anomalias da veia renal esquerda. A veia cava inferior se desenvolve da sexta à oitava semanas de gestação, originada de três veias embrionárias pareadas: veias subcardinais, supracardinais e pós-cardinais. A complexidade da ontogenia da veia cava inferior, com numerosas anastomoses entre essas três veias embrionárias, pode levar a uma grande variedade do retorno venoso do abdome e membros inferiores. Algumas dessas anomalias têm implicações clínicas e cirúrgicas significativas, associadas a outras anomalias congênitas, e em alguns casos, associadas a trombose venosa de membros inferiores, principalmente em pacientes adultos jovens. Foram revistos os exames de dez pacientes com anomalias da veia cava inferior, três deles com trombose venosa profunda de membros inferiores. Foram salientados os principais aspectos das anomalias da veia cava inferior, nos exames de tomografia computadorizada multidetectores e ressonância magnética, correlacionados com a embriologia e demonstrando as principais vias alternativas de drenagem venosa. O conhecimento das anomalias da veia cava inferior é fundamental na avaliação dos exames de imagem do abdome, evitando erros de interpretação e indicando a possibilidade de anomalias associadas, implicações clínicas e cirúrgicas. Unitermos: Veia cava inferior; Anormalidades congênitas; Trombose venosa.

Yang C, Trad HS, Mendonça SM, Trad CS. Congenital inferior vena cava anomalies: a review of findings at multidetector computed tomography and magnetic resonance imaging. Radiol Bras. 2013 Jul/Ago;46(4):227-233.

* Study developed at CEDIRP - Central de Diagnóstico Ribeirão Preto, Ribeirão Preto, SP, Brazil.

1. Specialist in Radiology and Imaging Diagnosis, Fellow PhD degree, Faculdade de Medicina de Ribeirão Preto da Universidade de São Paulo (FMRPUSP), Radiologist at CEDIRP - Centra de Diagnóstico Ribeirão Preto, Ribeirão Preto, SP, Brazil.

2. Titular Member of Colégio Brasileiro de Radiologia e Diagnóstico por Imagem (CBR), Radiologist at CEDIRP - Central de Diagnóstico Ribeirão Preto, Physician Assistant at Hospital das Clínicas da Faculdade de Medicina de Ribeirão Preto da Universidade de São Paulo (HC-FMRPUSP), Ribeirão Preto, SP, Brazil.

3. Specialist in Radiology and Imaging Diagnosis, Radiologist at CDPI - Clínica de Diagnóstico Por Imagem, Rio de Janeiro, $\mathrm{RJ}$, Brasil.

4. PhD, Titular Member of Colégio Brasileiro de Radiologia e Diagnóstico por Imagem (CBR), Radiologist and Responsible

\section{INTRODUCTION}

Congenital anomalies of the inferior vena cava (IVC) are uncommon, occurring in up to $8.7 \%$ of the population, as anomalies of the left renal vein are considered ${ }^{(\mathbf{1})}$.

\footnotetext{
Technician at CEDIRP - Central de Diagnóstico Ribeirão Preto, Ribeirão Preto, SP, Brazil.

Mailing Address: Dr. Henrique Simão Trad. Rua Maestro Vila Lobos, 515, Jardim São Luiz. Ribeirão Preto, SP, Brazil, 14020440. E-mail: hstrad@terra.com.br.

Received August 5, 2012. Accepted after revision January
} 4,2013
With a complex embryonic development, originated from multiple embryonic structures, several anatomic variations of the venous return from the abdomen and lower limbs may occur ${ }^{(1-6)}$. Some of these anomalies have significant clinical implications associated with other congenital anomalies, history of lower limb venous thrombosis and hematuria, sometimes determining changes in surgical planning ${ }^{(3,7-10)}$.

With the availability of multidetector computed tomography (MDCT) and mag- 
netic resonance imaging (MRI) volumetric techniques, the demonstration of IVC anomalies became easier ${ }^{(\mathbf{4}-\mathbf{6}, 11)}$. However, it is not uncommon for such findings not being described on radiological reports, a fact that may negatively impact the approach to patients. In the present study, a simplified review of IVC embryology is made, demonstrating the main congenital anomalies, with evaluation, presentation, and discussion of ten cases.

Computed tomography (CT) and MRI studies performed between 2008 and 2010 in ten patients with IVC anomalies were retrospectively reviewed.

All the CT images were acquired in a 16-row multidetector equipment, with volumetric acquisition of $1.25 \mathrm{~mm}$-thick slices without spacing, after intravenous injection of $100 \mathrm{ml}$ iodinated contrast agent. The MRI studies were performed in 1.5 tesla high-field equipment, with acquisition of T1-and T2-weighted images acquisition, MRI angiography and contrastenhanced volumetric gradient-echo, delayed phase sequences.

Among the ten patients, five were men and five were women, with ages ranging from 6 to 77 years (median of 42.5 years). Three patients had a history of deep venous thrombosis (DVT) of lower limbs, with ages of 25, 29 and 47 years (median of 29 years), and were submitted to the exams in order to clarify their condition. The remaining patients were submitted to the exams for other reasons, such as abdominal pain, hematuria and tumor staging.

Among the seven patients with no DVT history two presented agenesis of the IVC intrahepatic portion, three presented double IVC, one presented transposition of the IVC and another presented retrocaval ureter. The median age of such patients was 43 years, revealing that the anomalies without relevant clinical implications have a tendency to be incidentally found during investigations performed for other reasons. In such a group, one 30-year old patient had agenesis of the intrahepatic portion of the IVC associated with polysplenia, intestinal malrotation and pancreatic malformation.

Among the three patients with a history of DVT, one presented agenesis of the infrarenal portion only, another presented agenesis of the whole IVC and preserved intrahepatic portion only; and the third patient presented agenesis of the renal and suprarenal portions of the IVC. In the three cases, multiple, small retroperitoneal collateral vessels could be visualized. Further details on such findings are described on Table 1 and on Figures 2 thru 8.

\section{EMBRYOLOGY}

At later phases of its embryonic development, the IVC may be divided into four segments: hepatic, suprarenal, renal and infrarenal, originating from different embryonic structures. In a simplified way, the IVC originates from three pairs of veins, namely, postcardinal veins, subcardinal veins and supracardinal veins, which are dominant in the fourth, sixth and eighth gestational weeks, respectively. From the beginning through the end of the ontogenesis of the IVC, the pairs of embryonic veins present partial regression and anastomosis, contributing to the development of retroperitoneal vascular structures of the adult (Table 2 and Figure 1).

\section{IVC ANOMALIES}

\section{Intrahepatic IVC agenesis with azygos/ hemiazygos continuation}

Embryonically, there is a developmental failure of the subcardinal-hepatic anas-

Table 1 List of patients and main findings.

\begin{tabular}{|c|c|c|}
\hline \multicolumn{3}{|r|}{ Patients without DVT history } \\
\hline Sex & Age & Findings \\
\hline Male & 71 years & $\begin{array}{l}\text { Agenesis of intrahepatic IVC with drainage through the azygos vein; retroaortic } \\
\text { left renal vein }\end{array}$ \\
\hline Female & 42 years & $\begin{array}{l}\text { Agenesis of intrahepatic IVC with drainage through the azygos vein; } \\
\text { polysplenia, intestinal malrotation and pancreatic malformation }\end{array}$ \\
\hline Male & 30 years & $\begin{array}{l}\text { Persistent left IVC with continuation in the common iliac vein; there is a } \\
\text { small communicating vessel between the common iliac veins }\end{array}$ \\
\hline Female & 43 years & $\begin{array}{l}\text { Persistent left IVC up to the common iliac vein; presence of left internal iliac } \\
\text { branches from the right IVC }\end{array}$ \\
\hline Female & 6 years & $\begin{array}{l}\text { Persistent left IVC, with continuation in the azygos vein; retroaortic left renal } \\
\text { vein; continuity with the external iliac vein }\end{array}$ \\
\hline Male & 52 years & $\begin{array}{l}\text { IVC transposition (agenesis of infrarenal IVC with drainage through the left } \\
\text { IVC up to the renal vein) }\end{array}$ \\
\hline \multicolumn{3}{|r|}{ Patients with DVT history } \\
\hline Sex & Age & Findings \\
\hline Female & 25 years & $\begin{array}{l}\text { Agenesis of IVC, except in the intrahepatic portion, with drainage through } \\
\text { multiple retroperitoneal, gonadal and lumbar collaterals, through left renal } \\
\text { vein and splenic vein; thrombosis of common, internal and external iliac veins }\end{array}$ \\
\hline Female & 29 years & $\begin{array}{l}\text { Agenesis of infrarenal IVC, with drainage through retroperitoneal, lumbar } \\
\text { collaterals and markedly calibrous left gonadal vein; pelvic varices }\end{array}$ \\
\hline Male & 47 years & $\begin{array}{l}\text { Agenesis of renal and suprarenal IVC. Presence of calibrous vessels in the } \\
\text { retroperitoneum, with increased caliber of the lumbar and azygos/hemiazygos } \\
\text { veins }\end{array}$ \\
\hline
\end{tabular}

Table 2 IVC segmentation in relation to embryonic origin.

\begin{tabular}{ll}
\multicolumn{1}{c}{ Venous segment } & \multicolumn{1}{c}{ Embryonic origin } \\
\hline Intrahepatic IVC & $\begin{array}{l}\text { Derived from the right vitelline vein, which forms the hepato-car- } \\
\text { diac canal and finally the intrahepatic IVC } \\
\text { Derived from the right subcardinal vein, also forming the renal, } \\
\text { gonadal and adrenal veins }\end{array}$ \\
Infrarenal IVC & $\begin{array}{l}\text { Derived from the right supracardinal vein and from its anastomoses } \\
\text { with the subcardinal vein } \\
\text { Iliac veins }\end{array}$ \\
Azygos and hemiazygos veins & $\begin{array}{l}\text { Derived from the posterior cardinal veins } \\
\text { Derived from the cephalic portion of the supracardinal veins }\end{array}$
\end{tabular}




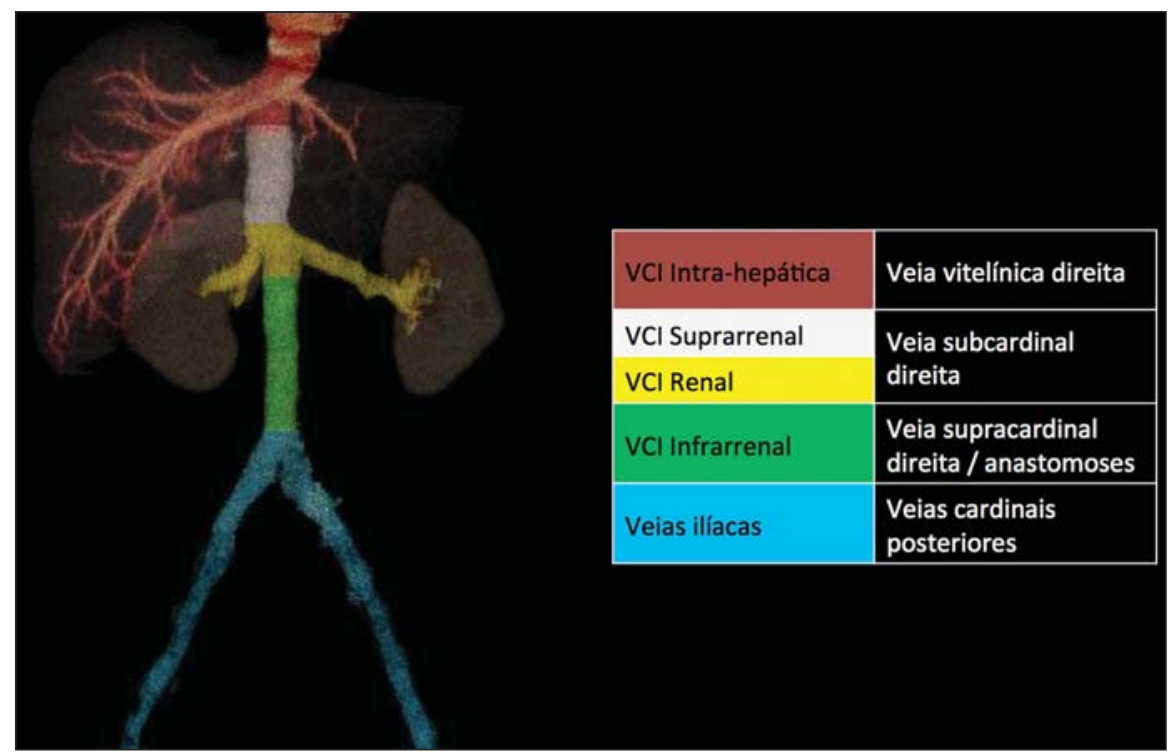

Figure 1. Three-dimensional reconstruction with volume rendering. The anatomic segments of the IVC are separately colored, with highlighted embryonic origins. tomosis between the suprarenal and hepatocardiac segments $^{(\mathbf{1}, \mathbf{6})}$. Consequently, blood is deviated to the retrocrural azygos vein which is dilated up to the arch, which joins the superior vena cava in the right paratracheal space. The posthepatic segment drains the suprahepatic veins directly into the right atrium.

Such an anomaly was classically described as being associated with polysplenia/asplenia and heterotaxy syndromes, with congenital cardiopathies and intestinal malrotation (Figure 2) ${ }^{(\mathbf{1}, \mathbf{4 , 6 , 8})}$. In such syndromes, the set of findings is variable from patient to patient, with reports of incidental findings, like in the case of the patient on Figure 2. With increasing utilization of imaging methods, such anomaly is found in asymptomatic patients with no other associated anomaly.

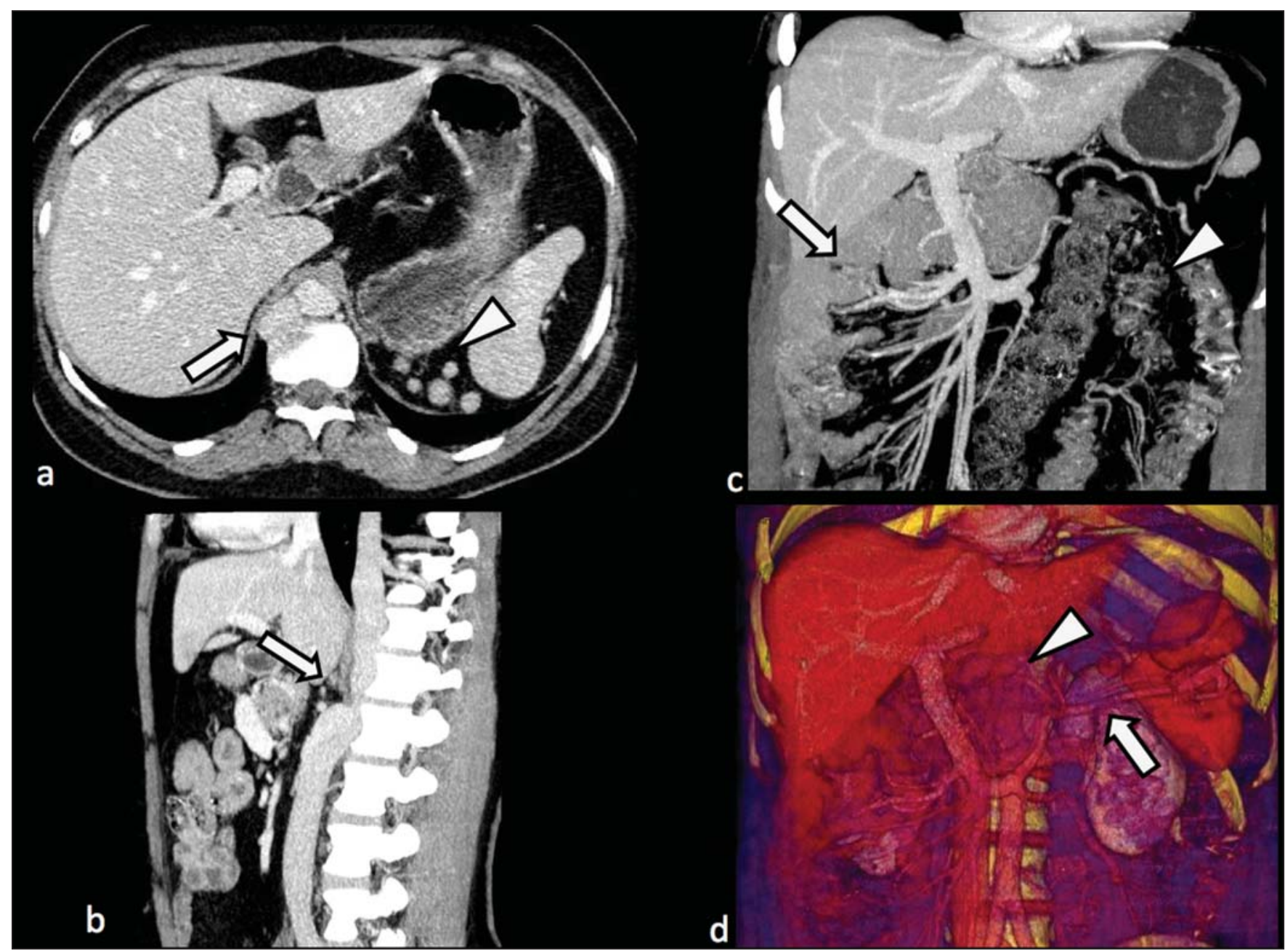

Figure 2. Intrahepatic IVC agenesis associated with polysplenia and intestinal malrotation. a: Dilated azygos vein on the axial section (arrow) and polysplenia (arrowhead). b: Sagittal MIP - IVC continuation with retrocrural, calibrous azygos vein (arrow); c: Coronal MIP - intestinal malrotation (arrow indicates small bowel loops; arrowhead indicates the colon). d: 3D coronal view - short pancreas (arrowhead) with splenic vein in inferior pathway (arrow). 


\section{Persistent left IVC}

It results from the persistence of right and left supracardinal veins, with two venae cavae around the infrarenal aorta ${ }^{(\mathbf{1}, 4,6)}$. Typically, the left IVC ends at the left renal vein, which anteriorly crosses the aorta to join the IVC (Figure3). Variations may occur, as in the case presented at Figure 3c, with retroaortic left renal vein and left IVC continuation with the azygos vein. The left ICV continues with the iliac veins, with variations in the anastomosis with the internal and external common iliac veins ${ }^{(2)}$.

\section{Transposition of the IVC}

It results from the regression of the right supracardinal vein and persistence of the left supracardinal vein. Typically, the left IVC ends at the left renal vein, which anteriorly crosses the aorta and forms a suprarenal IVC at right (Figure 4) ${ }^{(\mathbf{1})}$.

\section{Retroaortic/circumaortic left renal vein}

The left renal vein derives from the intersubcardinal anastomosis, which courses anteriorly to the aorta. Retroaortic left renal vein $(1.7 \%$ to $3.4 \%$ of the indi- viduals) occurs by regression of the intersubcardinal anastomosis and renal drainage through retroaortic intersupracardinal anastomosis ${ }^{(1,3)}$. The persistence of the two anastomoses results in a renal vein coursing anteriorly and another posteriorly to the aorta (prevalence of $2.4 \%$ to $8.7 \%$ ), with the retroaortic vein caudal in relation to the pre-aortic vein ${ }^{(1)}$ (Figure 3c).

\section{Retrocaval ureter}

It occurs exclusively in the right ureter and is one of the few IVC anomalies that

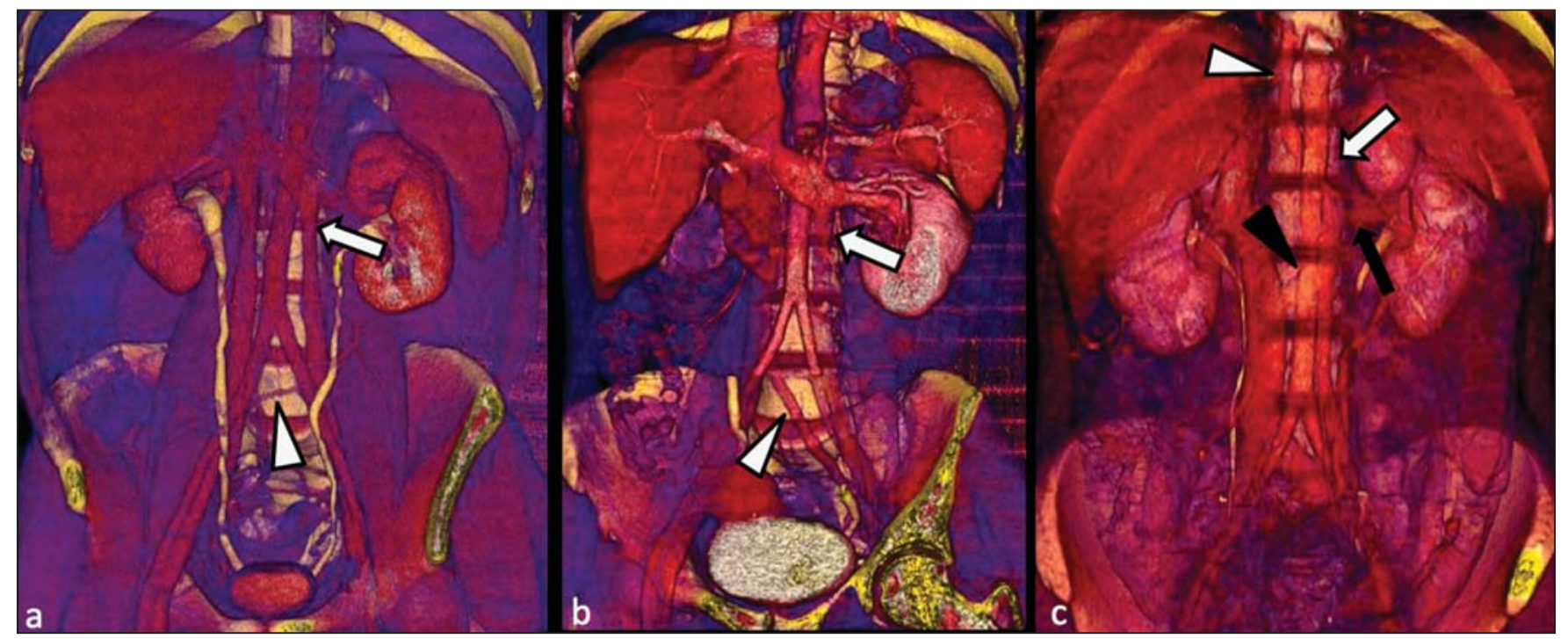

Figure 3. Persistent left IVC. Case 1 (a) - Left IVC draining into the left renal vein (arrow); small vessel anastomosis between the common iliac veins (arrowhead); Case 2 (b) - Left IVC draining into the left renal vein (arrow); branches from the left internal iliac joining the right IVC (arrowhead). Case 3 (c) - Left IVC with superior retroaortic pathway (white arrow) in continuation with the azygos vein (white arrowhead); left renal vein draining into the left IVC (black arrow) and there is a retroaortic communication between the inferior venae cavae, on the topography of retroaortic left renal vein (black arrowhead).

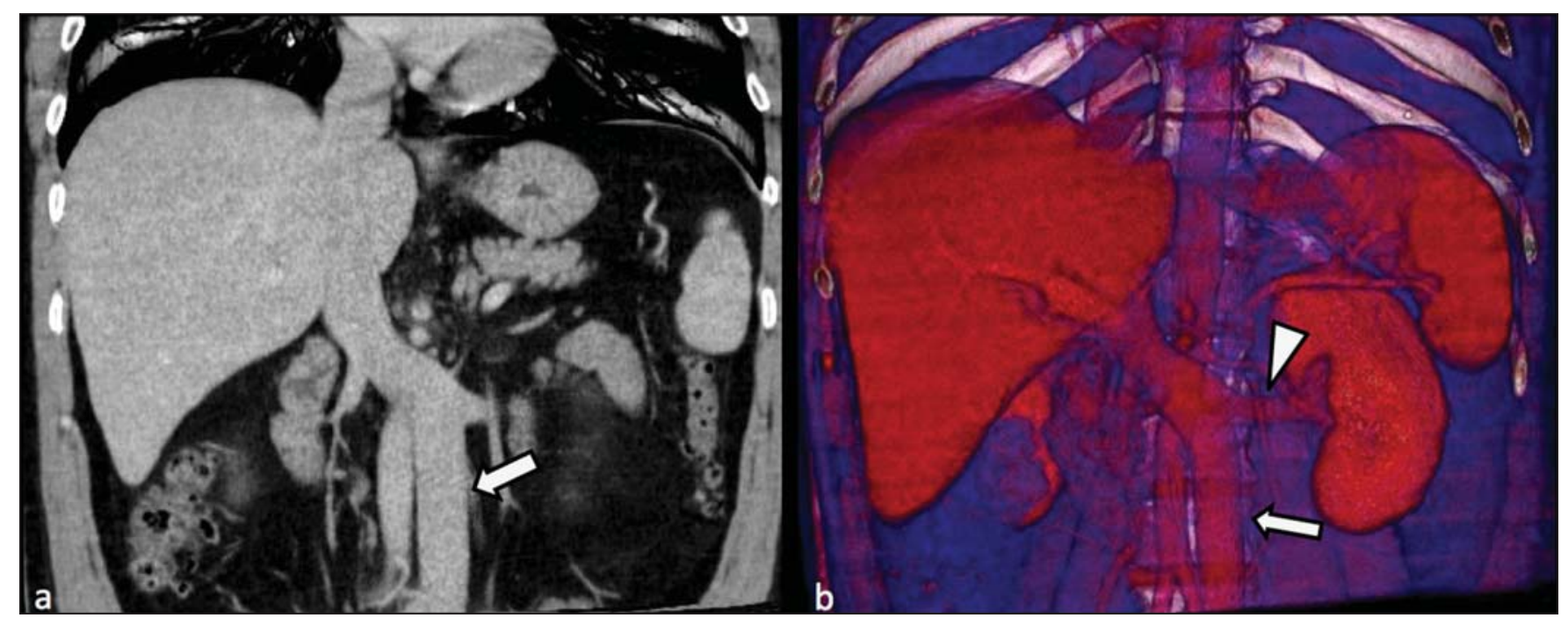

Figure 4. IVC transposition Coronal MIP (a) and 3D coronal image (b) demonstrate left IVC (arrows) draining into the left renal vein (arrowhead), anteriorly to the aorta. Absent right infrarenal IVC. The IVC is normally positioned at right of the renal, suprarenal and intrahepatic portions. 
may be symptomatic ${ }^{(\mathbf{1}, 4)}$. Along the development of the infrarenal IVC there is regression of the right supracardinal vein, which courses posteriorly and medially to the ureter, originating from the right posterior cardinal vein, which, by its turn, is anteriorly located in relation to the ureter, which is medially displaced (Figure 5). The ureter is fixed between the IVC and the aorta, with the possibility of ureteral stenosis, upstream hydronephrosis and recurrent urinary infections.

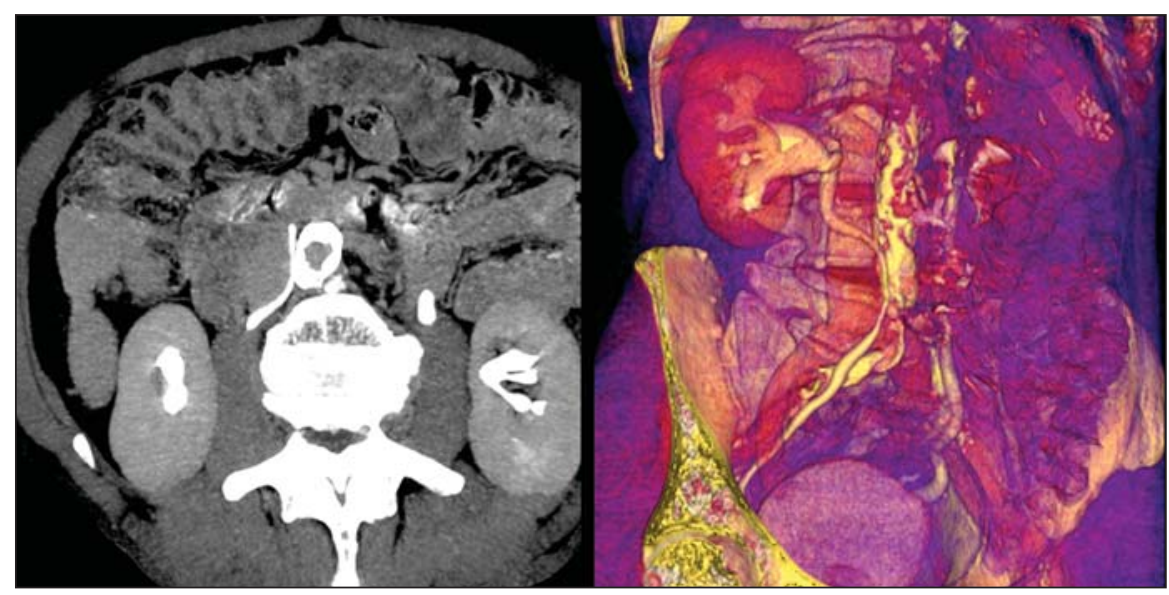

Figure 5. Retrocaval ureter. Right proximal ureter with posterior pathway to the IVC, crossing between the IVC and the middle third of the abdominal aorta.

\section{Subhepatic IVC agenesis}

Agenesis of subhepatic segments of the inferior vena cava may occur, involving the suprarenal, renal and infrarenal segments ${ }^{(\mathbf{1}, 4,7)}$. In the present series, the three cases with history of lower limbs venous thrombosis, the findings were agenesis of subhepatic segments, without definition of single calibrous retroperitoneal vessel which would assist in venous return. Multiple calibrous venous collaterals were visualized in the retroperitoneum, including gonadal veins, lumbar and pelvic varices, with increased caliber of the azygos/ hemiazygos system (Figures 6 thru 8).

\section{IVC ANOMALIES AND CLINICO- SURGICAL IMPLICATIONS}

Left-sided IVC may cause misdiagnosis with para-aortic lymph node enlargement, and may cause difficulties in the transjugular approach for IVC filter implantation.
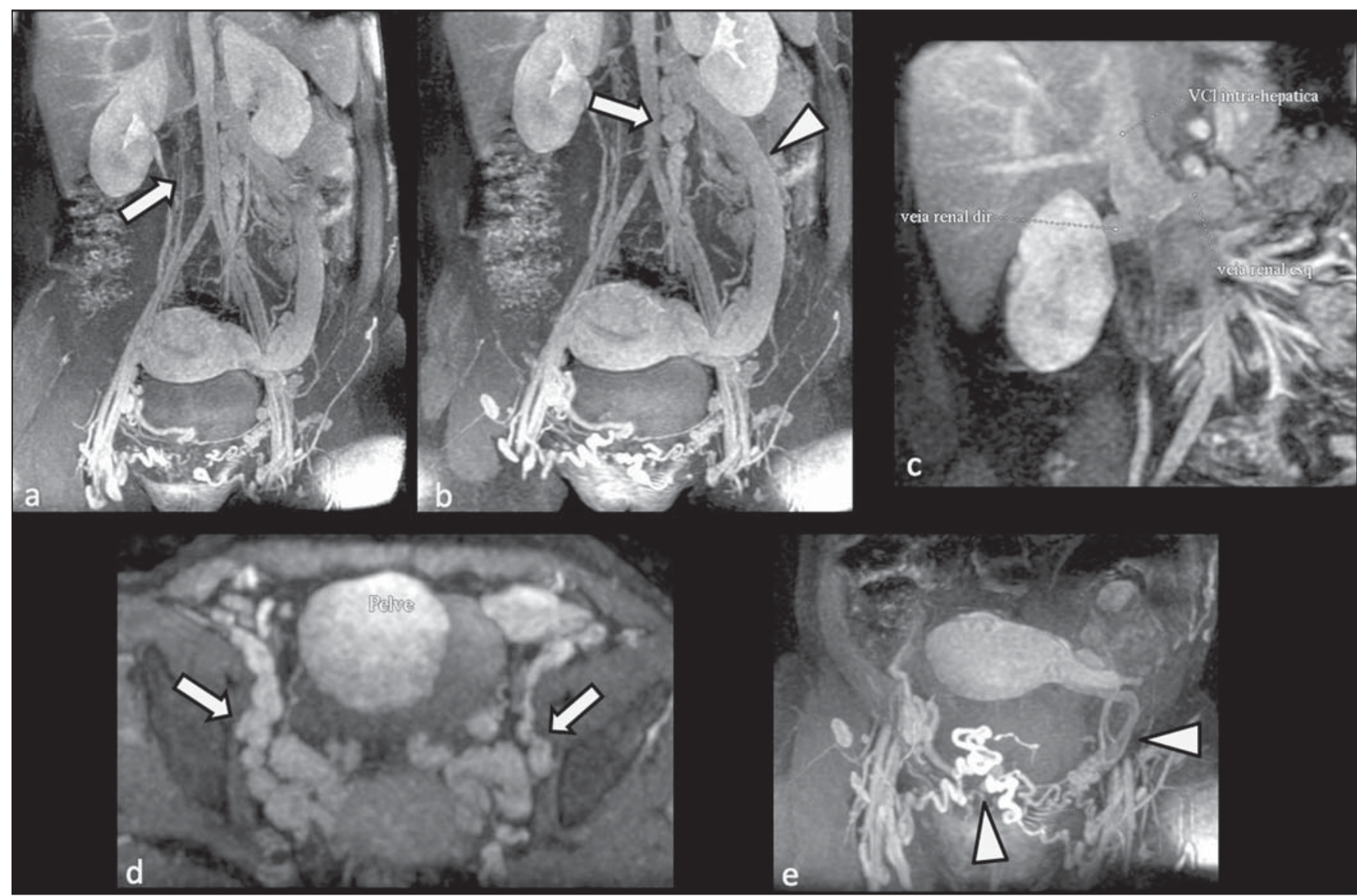

Figure 6. Agenesis of infrarenal IVC. MRI angiography MIP reconstruction of abdomen - Agenesis of infrarenal IVC (arrow on a); dilated retroperitoneal veins and markedly calibrous left gonadal vein (arrow and arrowhead on $\mathbf{b}$ ); magnification of the IVC occlusion area in the renal/infrarenal transition (c); pelvic varices (arrows in $\mathbf{d}$ ) and varices on the lower abdominal wall (arrowheads on $\mathbf{e}$ ). 

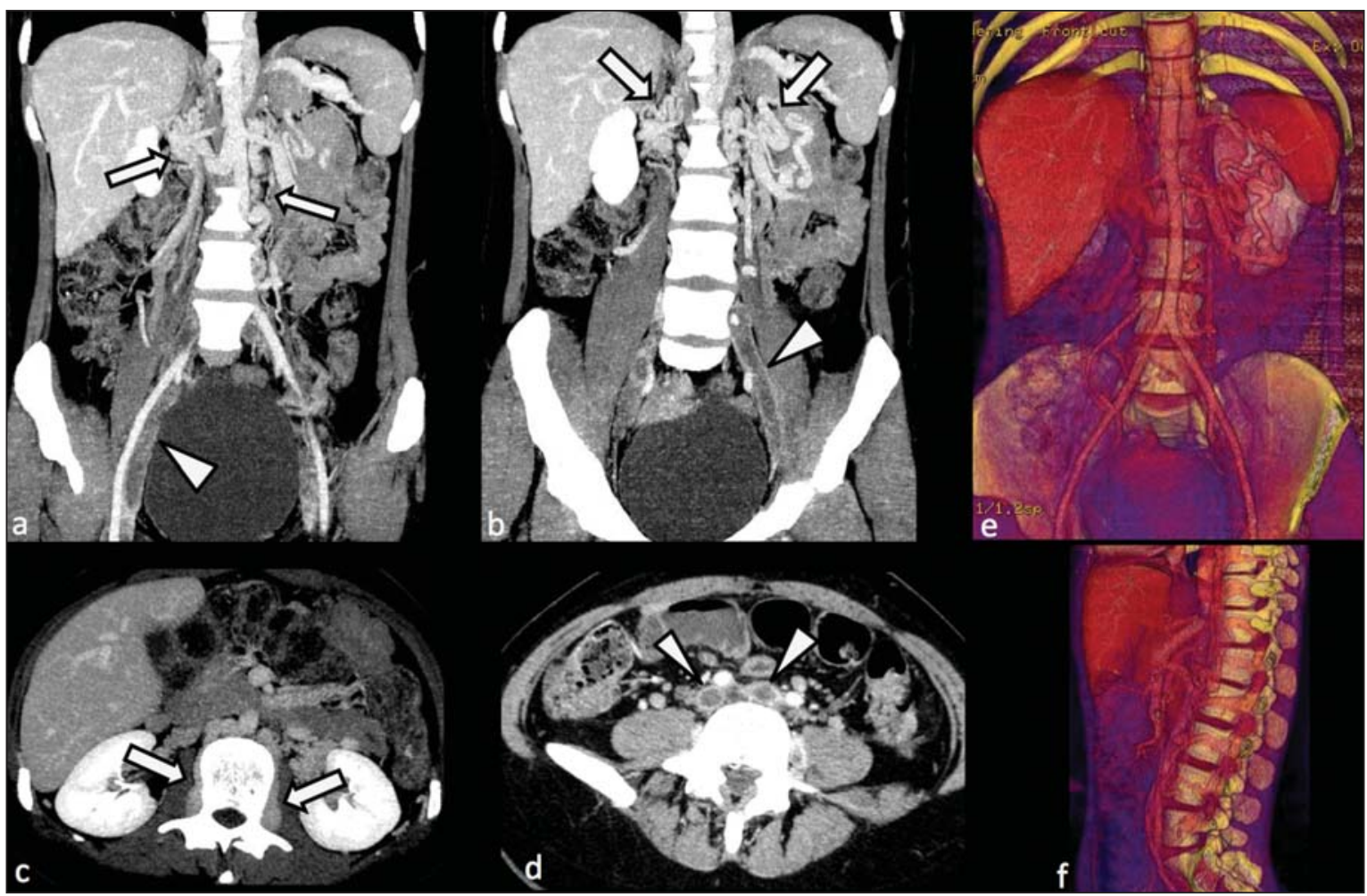

Figure 7. Agenesis of suprarenal, renal and infrarenal IVC. Coronal MIP (a,b) - presence of extensive, calibrous collaterals in the retroperitoneum (arrows); thrombosed iliac veins (arrowheads). Axial MIP (c,d) - presence of calibrous collaterals in the retroperitoneum with increased caliber of the lumbar veins (arrows on c); thrombosed common iliac veins (arrowheads on $\mathbf{d}$ ). 3D reconstruction - lumbar and retroperitoneal collaterals.

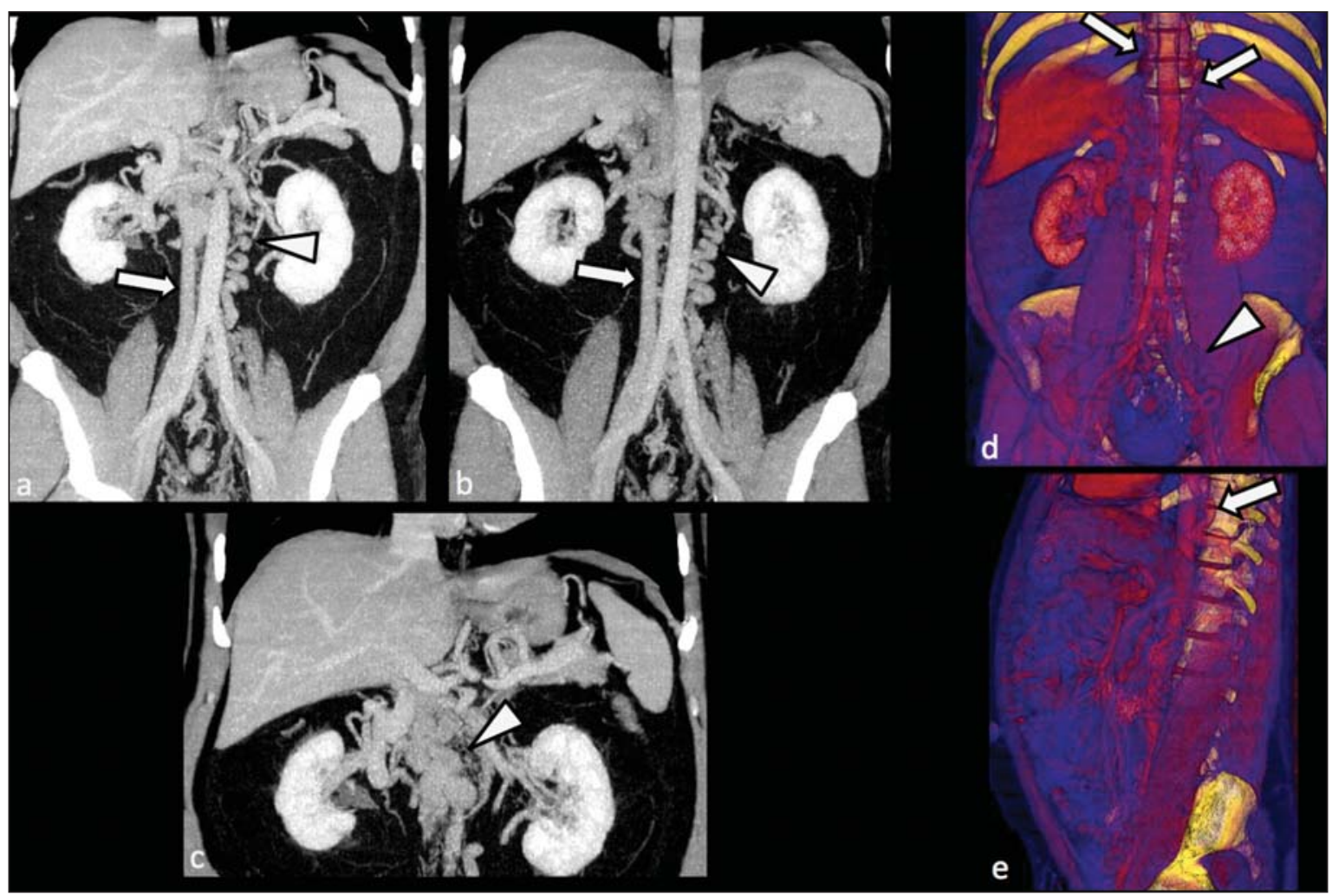

Figure 8. Agenesis of suprarenal and renal IVC. Coronal MIP (a,b,c) - infrarenal IVC (arrows) visible up to the renal hilum, with ill-defined suprarenal portion, and multiple calibrous vessels in the retroperitoneum (arrowheads). 3D reconstruction - calibrous, lumbar and retroperitoneal vessels, with increased caliber of the azygos and hemiazygos veins (arrows) pelvic varices (arrowheads). 
Also, it should be suspected whenever there is recurrent pulmonary thromboembolism in patients with implanted IVC filter.

Anomalies of (retroaortic and circumaortic) left renal vein have clinical relevance mainly in surgical planning and in renal vein catheterization. On rare occasions the compression of the retroaortic renal vein may result in periureteral varices, venous hypertension and hematuria.

Anomalies of the IVC were recognized as a possible risk factor for lower limb thrombosis, particularly in young adults. In some cases, the inappropriate venous return increases the pressure, leading to blood stasis in lower extremities and development of varices. Thrombosis occurs bilaterally in $50 \%$ of cases. An exuberant network of collaterals is generally identified, with prominent azygos and hemiazygos veins, ascending lumbar veins, internal paravertebral venous plexus and anterior abdominal wall veins. Markedly dilated lumbar veins may cause lumbar pain.

\section{CONCLUSION}

The evaluation of the retroperitoneum and its vessels is of extreme importance in the investigation of the abdomen. In spite of being uncommon, congenital IVC anomalies may cause difficulties in the interpretation of axial images. A basic knowledge of embryology and on the main congenital IVC anomalies is required for the correct interpretation and description by the radiologist, with special emphasis on alterations with possible clinical and surgical implications.

\section{REFERENCES}

1. Kellman GM, Alpern MB, Sandler MA, et al Computed tomography of vena caval anomalies with embryologic correlation. Radiographics. 1988;8:533-56.

2. Morita S, Higuchi M, Saito N, et al. Pelvic venous variations in patients with congenital inferior vena cava anomalies: classification with computed tomography. Acta Radiol. 2007;48:974-9.

3. Royal SA, Callen PW. CT evaluation of anomalies of the inferior vena cava and left renal vein. AJR Am J Roentgenol. 1979;132:759-63.
4. Kandpal H, Sharma R, Gamangatti S, et al. Imaging the inferior vena cava: a road less traveled. Radiographics. 2008;28:669-89.

5. Fernandez-Cuadrado J, Alonso-Torres A, Baudraxler F, et al. Three-dimensional contrast-enhanced magnetic resonance angiography of congenital inferior vena cava anomalies. Semin Pediatr Surg. 2005;14:226-32.

6. Bass JE, Redwine MD, Kramer LA, et al. Spectrum of congenital anomalies of the inferior vena cava: cross-sectional imaging findings. Radiographics. 2000;20:639-52.

7. Gayer G, Luboshitz J, Hertz M, et al. Congenital anomalies of the inferior vena cava revealed on $\mathrm{CT}$ in patients with deep vein thrombosis. AJR Am J Roentgenol. 2003;180:729-32.

8. Fulcher AS, Turner MA. Abdominal manifestations of situs anomalies in adults. Radiographics. 2002;22:1439-56.

9. Saad WE, Saad N. Computer tomography for venous thromboembolic disease. Radiol Clin North Am. 2007;45:423-45, vii

10. Applegate KE, Goske MJ, Pierce G, et al. Situs revisited: imaging of the heterotaxy syndrome. Radiographics. 1999;19:837-54.

11. Sheth S, Fishman EK. Imaging of the inferior vena cava with MDCT. AJR Am J Roentgenol. 2007; 189:1243-51. 